The University of San Francisco

USF Scholarship: a digital repository @ Gleeson Library | Geschke Center

2014

\title{
A Review of Recent Perspectives on Biomechanical Risk Factors Associated with Anterior Cruciate Ligament Injury
}

Gerwyn Hughes

University of San Francisco, ghughes@usfca.edu

Follow this and additional works at: https://repository.usfca.edu/ess

Part of the Sports Sciences Commons, and the Sports Studies Commons

\section{Recommended Citation}

Hughes, Gerwyn, "A Review of Recent Perspectives on Biomechanical Risk Factors Associated with Anterior Cruciate Ligament Injury" (2014). Kinesiology (Formerly Exercise and Sport Science). 48.

https://repository.usfca.edu/ess/48 


\section{A review of recent perspectives on biomechanical risk factors associated with}

\section{2 anterior cruciate ligament injury.}

\section{Abstract}

There is considerable evidence to support a number of biomechanical risk factors associated with non-contact anterior cruciate ligament $(A C L)$ injury. This paper aimed to review these biomechanical risk factors and highlight future directions relating to them. Current perspectives investigating trunk position and relationships between 9 strength, muscle activity and biomechanics during landing/cutting highlight the importance of increasing hamstring muscle force during dynamic movements through altering strength, muscle activity, muscle length and contraction velocity. In particular, increased trunk flexion during landing/cutting and greater hamstring strength are likely to increase hamstring muscle force during landing and cutting which have been associated with reduced $A C L$ injury risk. Decision making has also been shown to influence landing biomechanics and should be considered when designing tasks to assess landing/cutting biomechanics. Coaches should therefore promote hamstring strength training and active trunk flexion during landing and cutting in an attempt to reduce $A C L$ injury risk.

Keywords: strength, landing, trunk, knee. 


\section{Introduction}

Anterior cruciate ligament (ACL) injury is a common debilitating sports injury which often results in reduced knee function through the development of knee instability and subsequent damage to the menisci and articular surfaces (Irvine \& Glasgow, 1992; Smith, Livesay, \& Woo, 1988). Approximately $70 \%$ of ACL injuries have been reported to occur during non-contact situations, such as landing, deceleration and rapid change of direction (Griffin et al., 2000). Females have been shown to be 6 to 8 times more likely to sustain an ACL injury compared to males competing in the same sport (Arendt \& Dick, 1995). A number of biomechanical risk factors have been associated with this gender difference. Previous reviews have discussed gender differences in kinematics and kinetics during landing or cutting manoeuvres (as summarised in the first two sections of this review). However, more recent perspectives, such as investigation of the role of the trunk, the effects of decision making and the relationships between muscle strength, activity and landing/cutting biomechanics, have received little consideration in previous reviews. The purpose of this paper is to review the current evidence related to biomechanical risk factors associated with the gender difference in the incidence of ACL injury and highlight current perspectives relating to these biomechanical risk factors which require further investigation.

\section{Gender differences in landing and cutting kinematics}

A number of studies which have investigated the sagittal plane kinematics of landing and/or cutting manoeuvres report that females tend to contact the ground with the hips and knees more extended than males (Decker, Torry, Wyland, Sterett, \& 
Steadman, 2003; James, Sizer, Starch, Lockhart, \& Slauterbeck, 2004; Malinzak, Colby, Kirkendall, Yu \& Garrett, 2001; Yu, Lin, \& Garett, 2006). Contraction of the quadriceps, acting through the patellar tendon, produces an anteriorly directed shear force to the proximal tibia. For a given load acting through the patellar tendon, the less knee flexion, the greater the strain on the $A C L$ is likely to be due to the inverse relationship between knee flexion and the patella tendon-tibia shaft angle (angle between the long axis of the tibia and the line of action of the patellar tendon in the sagittal plane) (Li et al., 1999; Nunley, Wright, Renner, Yu, \& Garett, 2003). Furthermore, as knee flexion angle decreases, hamstring tendon-tibia shaft angle has been shown to decrease to the point where hamstring muscle force may increase the anterior shear force acting at the proximal tibia when the knee is close to full extension (Lin et al., 2012). Non-contact ACL injury has been reported to occur frequently when the knee is close to full extension (Boden, Dean, Feagin, \& Garett, 2000; Olsen, Mykelbust, Engebretsen, \& Bahr, 2004). Consequently, reduced knee flexion at initial ground contact in females may increase the risk of $A C L$ injury relative to males.

Studies which have investigated the frontal plane kinematics of landing/cutting report females to exhibit greater maximum knee valgus angle and greater range of motion of knee valgus when landing compared to males (Ford, Myer, \& Hewett, 2003; Hughes, Watkins, \& Owen, 2008; Kernozek, Torry, Van Hoof, Cowley, \& Tanner, 2005; Malinzak et al., 2001). Due to the structure of the knee, angular motion about an anteriorposterior axis (knee valgus/varus) is very limited, whereby the hamstring muscles tend to stabilise the knee the frontal plane (Lloyd \& Buchanan, 2001). Excessive valgus movement of the knee is likely to indicate reduced dynamic stability 
provided by the hamstrings and result in strain acting on the passive support structures, in particular the ACL. Boden et al. (2000) and Olsen et al. (2004) reported that non-contact ACL injury frequently occurs when the knee exhibits a valgus movement. Consequently, the greater maximum knee valgus angle and range of motion of knee valgus reported in females during landing/cutting may increase the risk of ACL injury relative to males. Finally, Pollard, Sigward, \& Powers (2010) reported that female subjects who exhibited low peak flexion angles (combined knee and hip flexion) during landing displayed significantly greater peak knee valgus angles. This suggests there may be an association between frontal and sagittal plane kinematics at the knee during landing which combine to increase $A C L$ injury risk in females.

\section{Gender differences in landing and cutting kinetics}

During landing, lower limb joint movements are determined by the resultant joint moments acting about the joints. Studies examining internal joint moments (moment produced about a joint by the internal structures within and crossing a joint) of the lower limbs during landing indicate that females tend to exhibit reduced hip extension moment and greater knee extension moment (Chappell, Yu, Kirkendall, \& Garett, 2002; Salci, Kentel, Heycan, Akin, \& Korkusus, 2004; Yu et al., 2006) than males, even when accounting for differences in body size. In the frontal plane, females tend to exhibit greater knee valgus moments during landing/cutting compared to males (Chappell et al., 2002; Earl, Monteiro, \& Snyder, 2007; Kernozek, et al., 2005; McLean, Huang, \& van den Bogert, 2005; McLean, Walker, \& van den Bogert, 2005; Pappas, Hagins, Sheikhzadeh, Nordin, \& Rose, 2007). Knee valgus moments have 
been shown to cause high loading of the ACL (Markolf et al., 1995; Mizuno, Andrish, van den Bogert, \& McLean, 2009).

The internal moment about a particular axis through a joint is the predominantly determined by the moment due to the various muscles which, in turn, depends on both the muscle forces and the moment arms of the muscles. Figure 1 shows the forces acting on the proximal end of the tibia due to the ACL, posterior cruciate ligament $(\mathrm{PCL})$, quadriceps and hamstrings and their moment arms in the sagittal plane when the knee is close to full extension, i.e., when non-contact ACL injury is most common.

Figure 1 about here.

Kellis and Baltzopoulos (1999) calculated the moment arms of the patella tendon and the hamstrings for ten male subjects in the sagittal plane during submaximal knee flexion-extension movement at very slow (non constant) angular velocity using videofluoroscopy. Moment arms were taken as the perpendicular distance between the muscle tendon and the central contact point of the tibiofemoral joint. Between 0$10^{\circ}$ of knee flexion, the mean moment arm of the patella tendon was found to be 36.9 $\pm 3.2 \mathrm{~mm}$ and the mean moment arm of the hamstrings was found to be $23.9 \pm 2.6$ $\mathrm{mm}$. Other studies report values ranging from $30 \mathrm{~mm}$ to $40 \mathrm{~mm}$ for the moment arm of the patella tendon (Grood, Suntay, \& Noyes, 1984; Herzog \& Read, 1993; Smidt, 1973) and ranges from $20 \mathrm{~mm}$ to $41.3 \mathrm{~mm}$ for the moment arm of the hamstrings 
120 (Herzog \& Read, 1993; Smidt, 1973; Wretenburg, Nemeth, Lamontagne, \& Lundin, 1996). These data suggests that the mechanical advantage of the quadriceps may be greater than that of the hamstrings. When the knee is in a flexed position (between $15^{\circ}$ and $60^{\circ}$ of knee flexion), since the hamstrings work with the ACL to prevent anterior dislocation of the proximal tibia relative to the distal femur ( $\mathrm{Li}$ et al., 1999), this reduced mechanical advantage of the hamstrings relative to the quadriceps may increase the risk of overloading the hamstring muscles, which in turn may cause increased anterior shear force on the proximal end of the tibia which may strain the ACL. However, at low knee flexion angles (less than 150), co-contraction of the hamstrings has been shown to not significantly reduce tibia anterior translation ( $\mathrm{Li}$ et al., 1999).

Figure 2 shows the forces acting on the proximal end of the tibia due to the ACL, PCL, semimembranosus, semitendinosus, gracilis and biceps femoris and their moment arms in the frontal plane when the knee is close to full extension, i.e., when non-contact $A C L$ injury is most common.

Figure 2 about here.

Wretenburg et al., (1996) calculated the moment arms of the semimembranosus, semitendinosus, gracilis and biceps femoris in the frontal plane for ten male and seven female subjects using MRI measurements. Moment arms were taken as the perpendicular distance between the muscle tendon and the central contact point of 
144 the tibiofemoral joint and were measured with no muscle contraction. The absolute 145 moment arms of the semimembranosus, semitendinosus, gracilis and biceps femoris 146 in the frontal plane were significantly greater in males than females. Even when normalised to height, the moment arms of all muscles were still greater in males than females. These data suggests that the mechanical advantage of the semimembranosus, semitendinosus, gracilis and biceps femoris in the frontal plane may be greater in males than females. Since these muscles work with the passive support structures of the knee to prevent abnormal movement of the knee joint in the frontal plane (Lloyd \& Buchanan, 2001), this reduced mechanical advantage in females compared to males may increase the risk of overloading the semimembranosus, semitendinosus, gracilis and biceps femoris, which in turn may increase the likelihood of an abnormal movement of the knee joint in the frontal plane which may strain the passive support structures of the knee.

In summary, ACL injury is likely to occur due to abnormal movement of the tibiofemoral joint. In the sagittal plane, an imbalance of quadriceps muscle force over hamstring muscle force resulting in anterior shear force acting on the proximal end of the tibia is likely to cause an abnormal movement of the tibiofemoral joint (anterior displacement of the tibia relative to the femur) which will increase ACL strain. The greater knee extension moment in females compared to males suggests females' quadriceps muscles produce greater force relative to the force due to the hamstrings than males. Therefore future research should focus on ways to increase knee flexion angle and reduce knee extension and valgus moments in females through increasing hamstring muscle forces, in particular those muscles which attach to the medial aspect of the tibia. Recent perspectives on examining biomechanical risk factors 
associated with ACL injury have focussed on investigation of the role of the trunk, the effects of decision making and the relationships between muscle strength, activity and landing/cutting biomechanics. Whilst many of the studies focussing on these recent perspectives have identified relationships between these independent variables and biomechanical variables that have previously been identified as being associated with the gender difference in ACL injury incidence (as described previously), limited direct investigation into gender effects has been conducted. Therefore it is proposed that future research should be conducted in these areas to clearly identify if gender differences exist within these new perspectives.

\section{The effects of trunk position and load on landing/cutting biomechanics}

Through analysis of videos in which ACL injury occurred, Hewett, Torg and Boden (2009) identified that non-contact ACL injury was associated with reduced forward trunk lean and greater trunk lateral flexion, where the body was shifted towards the landing leg at the time of injury. This is also supported by Boden et al., (2000) who found that at the time of $A C L$ injury the trunk tended to be upright and/or laterally flexed. Zazulak, Hewett, Reeves, Goldberg and Cholewicki (2007) prospectively examined the relationship between trunk control and $A C L$ injury by measuring trunk displacement after the release of a sudden force in a group of 277 collegiate athletes. Of the athletes measured, 25 sustained a knee injury and 6 sustained ACL injury (4 females and 2 males). Trunk displacements at $150 \mathrm{~ms}$ following release of the force and maximum trunk displacement were significantly greater in the knee injured, ligament injured and $A C L$ injured groups compared to the non injured athletes. Of the 
192

variables analysed, lateral displacement of the trunk was the strongest predictor of ligament injury.

Trunk flexion is likely to influence lower extremity biomechanics through altering hip extensor and knee flexor muscle function (Grasso, Zago, \& Lacquaniti, 2000; Lieberman, Raichlen, Pontzer, Bramble, \& Cutright-Smith, 2006; Paul, Salle, \& Frings-Dresen, 1996) and altering the moment due to the trunk about the lower extremity joints (Blackburn \& Padua, 2009). Flexion of the trunk is often accompanied by anterior pelvic tilt. Anterior pelvic tilt will lengthen the gluteus maximus muscle and the hamstring muscle group, influencing the force-length relationship of the these muscles, whereby these muscles are positioned in such a way as to increase their ability to exert force (Kulas, Hortobagyi, \& Devita, 2010). Therefore, increased trunk flexion during landing/cutting is likely to result in increased length of the hamstrings and gluteus maximus than when landing with less trunk flexion which, in turn, will increase muscle forces. This increased force production of the gluteus maximus and the hamstrings may result in increased hip extension moment, reduced knee extension moment and reduced knee valgus moment during landing, all of which have been proposed to be associated with reduced ACL loading (Chappell et al., 2002; Salci et al., 2004; Yu et al., 2006).

Trunk flexion is likely to influence the moment due to the trunk about the hip and knee in the sagittal plane. This occurs due to the centre of mass of the trunk moving forward with increased trunk flexion, causing the centre of mass of the trunk to move closer to the knee and further away from the hip in the horizontal plane. Since the 
216 moment due to the trunk will be the product of the weight of the trunk and the

217 horizontal distance between the centre of mass of the trunk and the joint centre (i.e.

218 the moment arm of the trunk), increased trunk flexion is likely to increase the moment

219 due to the trunk about the hip but decrease the moment due to the trunk about the 220 knee (Blackburn \& Padua, 2009).

222 Due to these factors, recent research examining lower extremity biomechanical risk

223 factors associated with ACL injury has therefore focused on the influence of trunk 224 load and trunk motion (Blackburn \& Padua, 2009; Chaudhari, Hearn, \& Andriacchi, 2005; Dempsey, Elliott, Munro, Steele, \& Lloyd, 2012; Janssen, Sheppard, Dingley, Chapman, \& Spratford, 2012; Kulas, et al., 2010; Kulas, Zalewski, Hortobagyi, \& Devita, 2008; Nagano, Ida, Akai, \& Fukubayashi, 2011; Shimokochi, Ambegaonkar, Meyer, Lee, \& Shultz, 2013). A summary of the reported effects of trunk flexion and trunk loading on lower extremity biomechanics during landing/cutting manoeuvres is shown in Table 1.

Table 1 about here.

The findings of these studies provide strong evidence that trunk loading and trunk position alters the lower extremity biomechanical risk factors associated with ACL injury. In particular, increased trunk load and reduced trunk flexion have been shown to be associated with increased knee anterior shear force during two-footed landing (Kulas et al., 2010) and increased ACL forces during single-leg squats (Kulas, 
Hortobagyi, \& DeVita, 2012). Initial findings examining relationships between frontal and transverse plane motion of the trunk with frontal plane loading of the knee when in single limb stance show some association between these variables. Chaudhari et al. (2005) report that preventing weight from moving over the plant leg through constraining arm movement may increase knee valgus loading in cutting whereas Dempsey et al. (2012) report a significant positive correlation between trunk lateral flexion towards landing leg and knee valgus moment during single leg landing.

247 Furthermore, Frank et al. (2013) reported increased knee varus moments were associated with limited trunk rotation away from the stance limb and towards the direction of travel during a cutting task. Therefore, further investigation is required to verify the relationship between trunk movement and knee loading in the frontal and

251 transverse planes during different tasks in which ACL injuries frequently occur and 252 further investigation is required to determine whether gender differences exist in trunk position during landing and cutting which may contribute to the gender difference in ACL injury incidence.

The relationships between muscle activity, strength and landing/cutting

\section{biomechanics}

During landing and cutting, while the quadriceps muscles contract to attempt to control knee flexion through eccentric contraction, co-contraction of the hamstrings is essential to prevent excessive ACL loading due to the anterior shear force produced by the quadriceps. Due to their attachments on the lateral and medial aspects of the tibia, the hamstring muscles also help control transverse and frontal plane motions of the knee (Lloyd \& Buchanan, 2001). For example, Louie and Mote (1987) found that 
co-contraction of the muscles surrounding the knee increased torsional stiffness of the knee joint and Olmstead, Weavers, Bryant, and Gouw (1986) found that contraction of the hamstrings to produce a relatively small flexion torque at the knee (less than $20 \%$ maximum torque) increased valgus stability of the knee. A combination of anterior shear force acting on the proximal tibia and valgus loading result in loading of the ACL exceeds the loading due to each of these factors independently (Berns, Hull, \& Patterson, 1992; Markolf et al., 1995) which further highlights the important role of the hamstring muscle group in the prevention of non contact ACL injury. A number of studies have reported females to posses lower strength of the hamstrings compared to males, even when normalised to body weight (Hakkinen, Kraemer, \& Newton, 1997; Huston \& Wojtys, 1996; Salci et al., 2004). Furthermore, lower hamstring to quadriceps strength ratio's have been observed in females compared to males and have been reported to be due to reduced hamstring strength in females rather than due to differences in quadriceps strength (Myer et al., 2009). Lower hamstring to quadriceps strength ratio's have been reported to be associated with greater frontal and transverse plane motion during dynamic activities (Hewett et al., 2005). Since muscle strength is modifiable, Hewett et al. (1996) investigated the effect of a plyometric training intervention on landing mechanics and lower limb strength. The results showed plyometric training significantly increased hamstring strength which was also associated with significant reductions in frontal plane knee loading during a landing task. However, recent reviews of the effects of training programs on ACL injury (Dai, Herman, Lui, Garrett, \& Yu, 2012; Donnelly et al., 2012) highlight that whilst many training programs result in altered lower extremity movement patters, the effect of these training programs on $A C L$ injury incidence is inconsistent and the mechanisms by which biomechanical risk factors 
are influenced by training is unclear. Furthermore, a systematic review by Stojanovic and Ostojic (2012) examining nine studies which investigated the effects of training on $\mathrm{ACL}$ injury concluded that multicomponent training programs which included balance, plyometrics, agility and strength components appeared to be the most effective. However, more research is required to further verify the effects of training programs on ACL injury incidence in both males and females.

The force a muscle produces during a landing or cutting manoeuvre depends on a number of factors; including muscle length, contraction velocity, muscle strength (maximal force output) and muscle activity (number of active motor units and their firing rate). Previous research indicates gender differences exist in muscle activity during landing/cutting, whereby females tend to exhibit greater quadriceps muscle activity and less hamstring muscle activity compared to males (Malinzak et al., 2001) which is likely to result in increase ACL loading. Recent research has attempted to explore the relationships between strength, muscle activity and landing biomechanics. For example, Wild et al. (2013) examined lower limb kinematics of the hip, knee and ankle, ACL forces and muscle activity of six lower limb muscles (Medial Gastrocnemius, Tibialis Anterior, Vastus Medialis, Rectus Femoris, Semitendinosis and Biceps Femoris) during a single-leg horizontal landing in high (n $=11)$ and low $(n=11)$ concentric hamstring strength groups of pubescent females. The results showed that the low hamstring strength group displayed significantly greater knee valgus angles at the time of maximum vertical and anterioposterior ground reaction forces (GRF), significantly less hip abduction moments at the time of maximum vertical GRF and significantly greater ACL force at the time of maximum anterioposterior GRF compared to the high hamstring strength group. No significant 
differences were observed in the time of onset of muscle activity and the time to peak amplitude between high and low strength groups. These results suggest that those with low hamstring strength display a reduced ability to control frontal plane alignment of the lower limb during landing despite similar timing of muscle activity. Therefore, for the muscles that control the stability and movement of the knee, differences in peak strength may have a greater influence on the prevention of excessive frontal plane motion and $A C L$ force than differences in the timing of muscle activity, however further investigation is needed to examine the magnitude of muscle activity to further investigate these relationships.

Since reduced hip extension moment and increased knee extension moment have been associated with the gender difference in the incidence of ACL injury, Stearns et al. (2013) examined the relationship between hip and knee extension isometric strength and extension moments of the hip and knee observed during a two-footed drop-jump task in 20 male and 20 female recreational athletes. The results showed females displayed a significantly greater knee to hip extension moment ratio during landing and a significantly greater knee to hip extension isometric strength ratio compared to males. The results also showed that there was a significant positive relationship between landing knee to hip extension moment ratio during landing and knee to hip isometric strength ratio. These findings suggest that gender differences in hip and knee extensor moments observed during landing may partly be explained by differences in strength and therefore strengthening of the muscles that control hip extension (Hamstrings and Gluteus Maximus) in females may be important to reduce the gender difference in the incidence on non-contact ACL injury. 
The hip external rotators and abductors help prevent excessive valgus knee motion during landing through eccentric control of the femur. Weakness and/or insufficient activation of these muscles in females may also contribute to the greater incidence of non-contact ACL injury in females. Some studies have found an association between reduced hip abduction and external rotation strength and increased knee valgus motion during landing (Jacobs, Uhl, Mattacola, Shapiro, \& Rayens, 2007; Wallace et al., 2008), however other studies have contradicted these findings (Bolgla, Malone, Umberger, \& Uhl, 2008; Lawrence, Kernozek, Miller, Torry, \& Reuteman, 2008; Patrek, Kernozek, Willson, Wright, \& Doberstein, 2011). The reason for the discrepancy between these studies may, in part, be due to a lack of association between the muscle force produced during a dynamic task and strength during isometric or isokinetic tests, since other factors will also influence muscle force during a dynamic task. Therefore, Homan et al. (2013) measured hip external rotation and abduction isometric strength and examined relationships between these factors and gluteal muscle activity, frontal plane angles of the hip and knee and transverse plane motion of the hip during a two legged drop jump landing. For hip abduction strength, no significant differences were observed in landing kinematics of the hip and knee between high and low strength groups, however, the high hip abduction strength group displayed significantly less gluteus medius EMG amplitude compared to the low strength group. For hip external rotation strength, the high strength group exhibited significantly less external rotation, valgus knee angles and gluteus maximum muscle activity than the low strength group. These results therefore suggest that individuals with reduced hip abduction strength may compensate for strength deficiencies through increased activation the hip abductors in an attempt to maintain frontal plane alignment during landing. 
365 Overall, studies examining the relationships between lower limb strength, muscle activity and landing/cutting biomechanics suggest that strengthening the hamstring muscles can be important in preventing $A C L$ injury through enhanced ability to control frontal plane motion and loading of the knee and reducing the net knee extension moment during landing/cutting. There is less evidence to support the relationship between hip abduction and external rotation strength in controlling knee motion and loading, suggesting that the activity of these muscles may be more important in controlling frontal plane motion of the knee, however further research is required to confirm these findings.

\section{The effects of decision making on landing/cutting biomechanics}

Initial research examining gender differences in landing and cutting biomechanics have used highly standardised tasks which are predictable and controlled, such as drop-landings and drop-jumps from a set height (Decker et al. 2003; Kernozek et al., 2005; Salci et al., 2004) or cutting at a pre-determined angle (James et al., 2004; Malinzak et al., 2001). Whilst these standardised tasks have allowed us a greater understanding of biomechanical risk factors associated with ACL injury through controlling a number of potentially confounding factors, minor variations in jump landing tasks have been show to significantly affect landing biomechanics (Cruz et al., 2013). These tasks do not reflect the random nature of sports where participants are often required to respond to a number of different stimuli simultaneously and have to make adjustments during landing/cutting activity in response to these stimuli. This has led to recent research examining landing biomechanics during anticipated 
and unanticipated tasks to investigate the effects of decision making on landing biomechanics (Brown, Palmieri-Smith, \& McLean, 2009; Houck, Duncan, \& De Haven, 2006; Mache, Hoffman, Hannigan, Golden, \& Pavol, 2013; McLean, Borotikar, \& Lucey, 2010). For example, Houck et al., (2006) compared trunk orientation in the frontal plane (trunk position relative to the global vertical position), trunk lateral flexion (trunk position relative to the pelvis segment), lateral foot placement, frontal plane hip angle along with hip and knee moments in the frontal plane during anticipated and unanticipated straight line walking and side cutting (approximately $50^{\circ}$ change of direction) tasks. The results showed that frontal plane trunk orientation was significantly greater and hip abduction was significantly lower during the unanticipated side-step task compared to all other tasks whereas trunk lateral flexion was relatively similar across all tasks. Frontal plane knee moments were also affected by the decision making, whereby close to initial ground contact, moments were in the valgus direction during unanticipated side-cutting compared to the moments being in the varus direction for all other tasks and knee valgus moments were lower during $10-30 \%$ of stance for unanticipated side-cutting task compared to when the side cut was anticipated. These findings suggest that frontal plane hip and knee biomechanics are affected by anticipation and that global trunk orientation is affected by altered lower limb positioning rather than by trunk lateral flexion during unanticipated cutting. However, the speed of the walking and cutting activities were fairly low (means of between $2.2 \mathrm{~m} / \mathrm{s}$ and $1.9 \mathrm{~m} / \mathrm{s}$ ). Since ACL injury is likely to occur during more dynamic activities it limits the validity of the findings of this study and more research needs to be done in activities more representative of tasks in which ACL injury is common. Also, as with Mache et al., (2013), all unanticipated task were completed after the anticipated tasks. The non-randomised order of the 
pre-planned and decision making conditions suggest that learning and fatigue effects may have occurred, limiting the strength of any conclusions made.

Decision making has also been found to influence knee valgus moment by McLean et al., (2010) who found the knee valgus moment measured during unanticipated single leg landings (stimulus for which leg to land on given approximately $650 \mathrm{~ms}$ before ground contact) was significantly greater than during anticipated single leg landings (stimulus for which leg to land on given approximately $5 \mathrm{~s}$ before ground contact). In addition, significant correlations were observed between the peak knee valgus moment measured during anticipated landings and pre-motor times (time between a light stimulus and muscle activation in response) measured during a choice reaction task (subjects were required to move either left or right from a standing position in response to a light stimulus) for both medial gastrocnemius and medial hamstrings. For both muscles, increased pre-motor times were associated with increased knee abduction moment during the push off phase of the landing. The findings of this study further strengthen the link between anticipation and knee valgus moments and highlight a potentially important link between the function of the medial muscles of the lower limb, in particular the medial hamstrings, during a reaction task and valgus moment at the knee during landing.

Since initial research suggests that decision making influences landing biomechanics, Brown et al. (2009) investigated the effects of altering the time prior to landing of an unanticipated stimulus. Thirteen male and thirteen female recreational athletes completed a task involving a $2 \mathrm{~m}$ forward jump which subjects were then 
437 required to land from in single limb stance and immediately perform a vigorous cut to 438 the opposite side to the leg which they had landed on. The landing leg were given to 439 the subjects in an anticipated condition (5 s prior to the task) and during three unanticipated conditions (approximately $600 \mathrm{~ms}, 500 \mathrm{~ms}$ and $400 \mathrm{~ms}$ prior to 441 landing), provided by a light stimulus in a randomised order. For task effects, the 442 results showed that at initial ground contact, subjects displayed significantly greater hip abduction and less hip flexion in unanticipated conditions compared to the anticipated conditions but there was no significant difference between the three unanticipated conditions. Also, peak hip and knee external rotation moments during the first $50 \%$ of the stance phase were significantly greater for two of the

447 unanticipated conditions (500 ms and $400 \mathrm{~ms}$ ) compared to the unanticipated condition. These results suggest that whilst the unanticipated nature of tasks affects landing biomechanics, the timing of the unanticipated stimulus did not show any effect on the biomechanics of landing within the time frames examined in this study.

451 Further investigation is needed into shorted pre-landing stimulus times to further 452 verify these findings.

454 These studies provide clear indication that decision making does influence the biomechanics of landing/cutting, therefore future research should investigate tasks involving an element of decision making to reflect game situations. Further investigation is required to confirm any differences between males and females in 458 responses to decision making during landing/cutting since many of the findings from 459 the studies involve complex interactions between multiple independent variables 460 such as decision making, gender and type of task. At times, this makes interpretation 
461 of the results difficult but highlights the multifactoral nature of biomechanical risk

462 factors associated with ACL injury.

\section{Conclusion}

465 There is general consensus that the biomechanical risk factors associated with the 466 gender difference in ACL injury incidence include less knee flexion at ground contact, 467 greater knee valgus motion, greater knee extension moment and greater knee valgus 468 moment in females than males during landing and cutting manoeuvres. Increasing 469 hamstring muscle force through altering strength, muscle activity, muscle length and 470 contraction velocity is likely to reduce these biomechanical risk factors. Recent 471 research has focussed on the influence of trunk motion and loading along with the 472 relationships between strength, muscle activity and landing/cutting biomechanics. 473 This research has shown that increased trunk flexion and greater hamstring strength 474 are associated with reduced $A C L$ injury risk. Decision making has also been shown 475 to influence landing biomechanics and should be considered when designing tasks to 476 assess landing/cutting biomechanics. Coaches should therefore concentrate on 477 strength training of the hamstrings and encouraging athletes to actively flex the trunk 478 through incorporating training activities which involve decision making during landing 479 and cutting movements in an attempt to reduce ACL injury risk. 


\section{References}

482

483

484

485

486

487

488

489

490

491

492

493

494

495

496

497

498

499

500

Arendt, E. A., \& Dick, R. (1995). Knee injury patterns among men and women in collegiate basketball and soccer. The American Journal of Sports Medicine, 23, 694-701.

Berns, G. S., Hull, M. L., \& Patterson, H. A. (1992). Strain in the anteromedial bundle of the anterior cruciate ligament under combination loading. Journal of Orthopaedic Research, 10(2), 167-176.

Blackburn, J. T., \& Padua, D. A. (2009). Sagittal-plane trunk position, landing forces, and quadriceps electromyographic activity. Journal of Athletic Training, 44(2), 174179.

Boden, B. P., Dean, G. S., Feagin, J. A., \& Garett, W. E. (2000). Mechanisms of anterior cruciate ligament injury. Orthopedics, 23, 573-578.

Bolgla, L. A., Malone, T. R., Umberger, B. R., \& Uhl, T. L. (2008). Hip strength and hip and knee kinematics during stair descent in females with and without patellofemoral pain syndrome. Journal of Orthopaedic \& Sports Physical Therapy, 38(1), 12-18.

Brown, T. N., Palmieri-Smith, R. M., \& McLean, S. G. (2009). Sex and limb differences in hip and knee kinematics and kinetics during anticipated and unanticipated jump landings: implications for anterior cruciate ligament injury. British Journal of Sports Medicine, 43(13), 1049-1056. 
501

502

503

504

505

506

507

508

509

510

511

512

513

514

515

516

517

518

519

Chappell, D. J., Yu, B., Kirkendall, D. T., \& Garett, W. E. (2002). A comparison of knee kinetics between male and female recreational athletes in stop-jump tasks. The American Journal of Sports Medicine, 30(2), 261-267.

Chaudhari, A. M., Hearn, B. K., \& Andriacchi, T. P. (2005). Sport-dependent variations in arm position during single-limb landing influence knee loading: implications for anterior cruciate ligament injury. The American Journal of Sports Medicine, 33(6), 824-830.

Cruz, A., Bell, D., McGrath, M., Blackburn, T., Padua, D., \& Herman, D. (2013). The effects of three jump landing tasks on kinetic and kinematic measures: Implications for ACL injury research. Research in Sports Medicine: An International Journal, 21(4), 230-234.

Dai, B., Herman, D., Lui, H., Garrett, W. E., and Yu, B. (2012). Prevention of ACL injury, part II: Effects of ACL injury prevention programs on neuromuscular risk factors and injury rate. Research in Sports Medicine: An International Journal, 20(3-4), 198-222.

Decker, M. J., Torry, M. R., Wyland, D. J., Sterett, W. I., \& Steadman, J. R. (2003). Gender differences in lower extremity kinematics, kinetics and energy absorption during landing. Clinical Biomechanics, 18, 662-669.

Dempsey, A. R., Elliott, B. C., Munro, B. J., Steele, J. R., \& Lloyd, D. G. (2012). Whole body kinematics and knee moments that occur during an overhead catch and landing task in sport. Clinical Biomechanics, 27(5), 466-474.

Donnelly, C. J., Elliot, B. C., Ackland, T. R., Doyle, T. L. A., Beiser, T. F., Finch, C. F., Cochrane, J. L., Dempsey, A. R., \& Lloyd, D. G. (2012). An anterior cruciate 
ligament injury prevention framework: Incorporating the recent evidence. Research in Sports Medicine: An International Journal, 20(3-4), 239-262.

Earl, J. E., Monteiro, S. K., \& Snyder, K. R. (2007). Differences in lower extremity kinematics between a bilateral drop-vertical jump and a single-leg step-down. Journal of Orthopaedic \& Sports Physical Therapy, 37(5), 245-252.

Ford, K. R., Myer, G. D., \& Hewett, T. E. (2003). Valgus knee motion during landing in high school female and male basketball players. Medicine and Science in Sport and Exercise, 1745-1750.

Frank, B., Bell, D. R., Norcross, M. F., Blackburn, J. T., Goerger, B. M., \& Padua, D. A. (2013). Trunk and hip biomechanics influence anterior cruciate ligament loading mechanisms in physically active participants. The American Journal of Sports Medicine, 41.

Grasso, R., Zago, M., \& Lacquaniti, F. (2000). Interactions between posture and locomotion: motor patterns in human walking with bent posture versus erect posture. Journal of Neurophysiology, 83, 288-300.

Griffin, L. Y., Angel, J., Albohm, M. J., Arendt, E. A., Dick, R. W., Garrett, W. E., et al. (2000). Noncontact anterior cruciate ligament injuries: risk factors and prevention strategy. Journal of the American Academy of Orthopaedic Surgeons, 8(3), 141-150.

Grood, E. S., Suntay, W. J., \& Noyes, F. R. (1984). Biomechanics of the knee extension exercise: effect of cutting the anterior cruciate ligament. Journal of Bone Joint Surgery, 66, 725-734. 
546 Hakkinen, K., Kraemer, W. J., \& Newton, R. U. (1997). Muscle activation and force production during bilateral and unilateral concentric and isometric contractions and Clinical Neurophysiology, 37, 131-142.

Herzog, W., \& Read, L. (1993). Lines of action and moment arms of the major forcecarrying structures crossing the human knee joint. Journal of Anatomy, 182, 213-230.

Hewett, T. E., Myer, G. D., Ford, K. R., Heidt, R. S., Colosimo, A. J., McLean, S. G., et al. (2005). Biomechanical measures of neuromuscular control and valgus loading of the knee predict anterior cruciate ligament injury risk in female athletes: a prospective study. The American Journal of Sports Medicine, 33(4), 492-501.

Hewett, T. E., Stroupe, A. L., Nance, T. A., \& Noyes, F. R. (1996). Plyometric training in female athletes: decreased impact forces and increasing hamstring torques. The American Journal of Sports Medicine, 24(6), 765-773.

Hewett, T. E., Torg, J. S., \& Boden, B. P. (2009). Video analysis of trunk and knee motion during non-contact anterior cruciate ligament injury in female athletes: lateral trunk and knee abduction motion are combined components of the injury mechanism. British Journal of Sports Medicine, 43(6), 417-422.

Homan, K. J., Norcross, M. F., Goerger, B. M., Prentice, W. E., \& Blackburn, J. T. (2013). The influence of hip strength on gluteal activity and lower extremity kinematics. Journal of Electromyography and Kinesiology, 23(2), 411-415. 
568 Houck, J. R., Duncan, A., \& De Haven, K. E. (2006). Comparison of frontal plane

569

570

571

572

573

574

575

576

577

578

579

580

581

582

583

584

585

586

587 trunk kinematics and hip and knee moments during anticipated and unanticipated walking and side step cutting tasks. Gait \& Posture, 24(3), 314322.

Hughes, G., Watkins, J., \& Owen, N. (2008). Gender differences in lower limb frontal plane kinematics during landing. Sports Biomechanics, 7(3), 333-341.

Huston, L. J., \& Wojtys, E. M. (1996). Neuromuscular performance characteristics in elite female athletes. The American Journal of Sports Medicine, 24, 427-436.

Irvine, L. B., \& Glasgow, M. M. (1992). The natural history of the meniscus in the anterior cruciate insufficiency. Journal of Bone Joint Surgery, 74A, 403-405.

Jacobs, C. A., Uhl, T. L., Mattacola, C. G., Shapiro, R., \& Rayens, W. S. (2007). Hip abductor function and lower extremity landing kinematics: Sex differences. Journal of Athletic Training, 42(1), 76-83.

James, C. R., Sizer, P. S., Starch, D. W., Lockhart, T. E., \& Slauterbeck, J. (2004). Gender differences among sagittal plane knee kinematics and ground reaction force characteristics during a rapid sprint and cut maneuver. Research Quarterly for Exercise and Sport, 8, 31-39.

Janssen, I., Sheppard, J. M., Dingley, A. A., Chapman, D. W., \& Spratford, W. (2012). Lower extremity kinematics and kinetics when landing from unloaded and loaded jumps. Journal of Applied Biomechanics, 28(6), 687-693. 
Kellis, E., \& Baltzopoulos, V. (1999). In vivo determination of the patella tendon and hamstring moment arms in adult males using videofluoroscopy during submaximal knee extension and flexion. Clinical Biomechanics, 14, 118-124.

Kernozek, T. W., Torry, M. R., Van Hoof, H., Cowley, H., \& Tanner, S. (2005). Gender differences in frontal plane and sagittal plane biomechanics during drop landings. Medicine and Science in Sport and Exercise, 37(6), 1003-1012.

Kulas, A., Hortobagyi, T., \& Devita, P. (2010). The interaction of trunk-load and trunkposition adaptations on knee anterior shear and hamstrings muscle forces during landing. Journal of Athletic Training, 45(1), 5-15.

Kulas, A., Hortobagyi, T., \& DeVita, P. (2012). Trunk position modulates anterior cruciate ligament forces and strains during a single-leg squat. Clinical Biomechanics, 27(1), 16-21.

Kulas, A., Zalewski, P., Hortobagyi, T., \& Devita, P. (2008). Effects of added trunk load and corresponding trunk position adaptations on lower extremity biomechanics during drop-landings. Journal of Biomechanics, 41, 180-185.

Lawrence, R. K., Kernozek, T. W., Miller, E. J., Torry, M. R., \& Reuteman, P. (2008). Influences of hip external rotation strength on knee mechanics during single-leg drop landings in females. Clinical Biomechanics, 23(6), 806-813.

Li, G., Rudy, T. W., Sakane, M., Kanamori, A., Ma, C. B., \& Woo, S. L. Y. (1999). The importance of quadriceps and hamstring muscle loading on knee kinematics and in-situ forces in the ACL. Journal of Biomechanics, 32, 395-400. 
Lieberman, D. E., Raichlen, D. A., Pontzer, H., Bramble, D. M., \& Cutright-Smith, E. (2006). The human gluteus maximus and its role in running. Journal of Experimental Biology 209, 2143-2155.

Lin, C-F., Lui, H., Gros, M. T., Weinhold, P., Garrett, W. E., \& Yu, B. (2012). Biomechanical risk factors of non-contact ACL injuries: A stochastic biomechanical modelling study. Journal of Sport and Health Science, 1, 36-42.

Lloyd, D. G., \& Buchanan, T. S. (2001). Strategies of muscular support of varus and valgus isometric loads at the human knee. Journal of Biomechanics, 34(10), 1257-1267.

Louie, L. K., \& Mote, C. D. (1986). Contribution of the musculature to rotary laxity and torsional stiffness at the knee. Journal of Biomechanics, 20(3), 281-300.

Mache, M. A., Hoffman, M. A., Hannigan, K., Golden, G. M., \& Pavol, M. J. (2013). Effects of decision making on landing mechanics as a function of task and sex. Clinical Biomechanics, 28(1), 104-109.

Malinzak, R. A., Colby, S. M., Kirkendall, D. T., Yu, B., \& Garrett, W. E. (2001). A comparison of knee joint motion patterns between men and women in selected athletic tasks. Clinical Biomechanics, 16, 438-445.

Markolf, K. L., Burchfield, D. I., Shapiro, M. M., Shepard, M. E., Finerman, G. A. M., \& Slauterbeck, J. L. (1995). Combined knee loading states that generate high anterior cruciate ligament forces. Journal of Orthopaedic Research, 13(6), 930935. 
630 McLean, S. G., Borotikar, B., \& Lucey, S. M. (2010). Lower limb muscle pre-motor

631

632

633

634

635

636

637

638

639

640

641

642

643

644

645

646

647

648

649

650 time measures during a choice reaction task associate with knee abduction loads during dynamic single leg landings. Clinical Biomechanics, 25(6), 563569.

McLean, S. G., Huang, X. M., \& van den Bogert, A. J. (2005). Association between lower extremity posture at contact and peak knee valgus moment during sidestepping: Implications for ACL injury. Clinical Biomechanics, 20(8), 863870.

McLean, S. G., Walker, K. B., \& van den Bogert, A. J. (2005). Effect of gender on lower extremity kinematics during rapid direction changes: an integrated analysis of three sports movements. Journal of Science and Medicine in Sport, $8(4), 411-422$.

Mizuno, K., Andrish, J. T., van den Bogert, A. J., \& McLean, S. G. (2009). Gender dimorphic ACL strain in response to combined dynamic 3D knee joint loading: Implications for ACL injury risk. Knee, 16(6), 432-440.

Myer, G. D., Ford, K. R., Foss, K. D. B., Liu, C., Nick, T. G., \& Hewett, T. E. (2009). The relationship of hamstrings and quadriceps strength to anterior cruciate ligament injury in female athletes. Clinical Journal of Sport Medicine, 19(1), 3-8.

Nagano, Y., Ida, H., Akai, M., \& Fukubayashi, T. (2011). Relationship between threedimensional kinematics of knee and trunk motion during shuttle run cutting. Journal of Sports Sciences, 29(14), 1525-1534. 
651 Nunley, R. M., Wright, D., Renner, J. B., Yu, B., \& Garett, W. E. (2003). Gender

652

653

654

655

656

657

658

659

660

661

662

663

664

665

666

667

668

669

670

671 comparison of pattella tendon tibial shaft angle with weight bearing. Research in Sports Medicine: An International Journal, 11(3), 173-185.

Olmstead, T. G., Weavers, H. W., Bryant, J. T., \& Gouw, G. J. (1986). Effect of muscular activity on valgus/varus laxity and stiffness of the knee. Journal of Biomechanics, 19(8), 565-577.

Olsen, O. E., Mykelbust, G., Engebretsen, L., \& Bahr, R. (2004). Injury mechanisms for anterior cruciate ligament injuries in team hanball: A systematic video analysis. The American Journal of Sports Medicine, 32(4), 1002-1012.

Pappas, E., Hagins, M., Sheikhzadeh, A., Nordin, M., \& Rose, D. (2007). Biomechanical differences between unilateral and bilateral landings from a jump: Gender differences. Clinical Journal of Sport Medicine, 17(4), 263-268.

Patrek, M. F., Kernozek, T. W., Willson, J. D., Wright, G. A., \& Doberstein, S. T. (2011). Hip-abductor fatigue and single-leg landing mechanics in women athletes. Journal of Athletic Training, 46(1), 31-42.

Paul, J. A., Salle, H., \& Frings-Dresen, M. H. W. (1996). Effect of posture on hip joint moment during pregnancy, while performing a task. Clinical Biomechanics, 11, 111-115.

Pollard, C. D., Sigward, S. M., \& Powers, C. M. (2010). Limited hip and knee flexion during landing is associated with increased frontal plane knee motion and moments. Clinical Biomechanics, 25, 142-146. 
672 Salci, Y., Kentel, B. B., Heycan, C., Akin, S., \& Korkusus, F. (2004). Comparison of

673

674

675

676

677

678

679

680

681

682

683

684

685

686

687

688

689

690

691

692 landing maneuvers between male and female college volleyball players. Clinical Biomechanics, 19(6), 622-628.

Shimokochi, Y., Ambegaonkar, J. P., Meyer, E. G., Lee, S. Y., \& Shultz, S. J. (2013). Changing sagittal plane body position during single-leg landings influences the risk of non-contact anterior cruciate ligament injury. Knee Surgery Sports Traumatology Arthroscopy, 21(4), 888-897.

Smidt, J. G. (1973). Biomechanical analysis of knee joint flexion and extension. Journal of Biomechanics, 6, 79-92.

Smith, B. A., Livesay, G. A., \& Woo, S. L. Y. (1988). Biology and biomechanics of the anterior cruciate ligament. Clinical Sports Medicine, 12, 637-666.

Stearns, K. M., Keim, R. G., \& Powers, C. M. (2013). Influence of relative hip and knee extensor muscle strength on landing biomechanics. Medicine and Science in Sports and Exercise, 45(5), 935-941.

Stojanovic, M. D., \& Ostojic, S. M. (2012). Preventing ACL injuries in team sport athletes: A systematic review of training interventions. Research in Sports Medicine: An International Journal, 20(3-4), 223-238.

Wallace, B. J., Kernozek, T. W., Mikat, R. P., Wright, G. A., Simons, S. Z., \& Wallace, K. L. (2008). A comparison between back squat exercise and vertical jump kinematics: implications for determining anterior cruciate ligament injury risk. Journal of Strength and Conditioning Research, 22(4), 1249-1258. 
693 Wild, C. Y., Steele, J. R., \& Munro, B. J. (2013). Insufficient hamstring strength compromises landing technique in adolescent girls. Medicine and Science in Sports and Exercise, 45(3), 497-505.

696

697

698

699

700

701

702

703

704

705

706

Wretenburg, P., nemeth, G., Lamontagne, M., \& Lundin, B. (1996). Passive knee muscle moment arms measured in vivo with MRI. Clinical Biomechanics, 11(8), 439-446.

Yu, B., Lin, C.-F., \& Garett, W. E. (2006). Lower extremity biomechanics during the landing of a stop-jump task. Clinical Biomechanics, 21, 297-305.

Zazulak, B. T., Hewett, T. E., Reeves, N. P., Goldberg, B., \& Cholewicki, J. (2007). Deficits in neuromuscular control of the trunk predict knee injury risk - A prospective biomechanical-epidemiologic study. American Journal of Sports Medicine, 35(7), 1123-1130. 


\section{Figure Captions}

708

709

710

711

712

Figure 1. The forces acting on the proximal end of the tibia due to the quadriceps and hamstrings and their moment arms in the sagittal plane. $F_{Q}=$ force exerted by the quadriceps, $F_{H}=$ force exerted by the hamstrings, $d_{Q}=$ moment arm of the quadriceps (patella tendon), $d_{H}=$ moment arm of the hamstrings, $A C L=$ force exerted by the ACL and $P C L=$ force exerted by the PCL.

Figure 2. Anterior aspect of the proximal end of the left tibia and the forces acting on the proximal end of the tibia due to the semimembranosus, semitendinosus, gracilis and biceps femoris and their moment arms in the frontal plane. $F_{S M}=$ force exerted by the semimembranosus, $F_{S T}=$ force exerted by the semitendinosus, $F_{G R}=$ force exerted by the gracilis, $F_{B F}=$ force exerted by the biceps femoris, $d_{S M}=$ moment arm of the semimembranosus, $d_{S T}=$ moment arm of the semitendinosus, $d_{G R}=$ moment arm of the gracilis, $d_{B F}=$ moment arm of the biceps femoris, $A C L=$ force exerted by the $A C L$ and $P C L=$ force exerted by the PCL. 


\begin{tabular}{|c|c|c|c|}
\hline Study & Task & $\begin{array}{l}\text { Independent } \\
\text { variables }\end{array}$ & Key findings \\
\hline $\begin{array}{l}\text { Chaudhari et } \\
\text { al. (2005) }\end{array}$ & $90^{\circ}$ cutting & $\begin{array}{l}\text { Arm position (no } \\
\text { constraint, holding } \\
\text { ball in each arm, } \\
\text { holding lacrosse } \\
\text { stick) }\end{array}$ & $\begin{array}{l}\text { Constraining plant side arm movement } \\
\text { increased knee valgus moment }\end{array}$ \\
\hline $\begin{array}{l}\text { Jansen et al. } \\
\text { (2012) }\end{array}$ & $\begin{array}{l}\text { Two footed } \\
\text { volleyball block } \\
\text { jump landing }\end{array}$ & $\begin{array}{l}\text { Load }(9.89 \mathrm{~kg} \\
\text { weighted vest) }\end{array}$ & $\begin{array}{l}\text { Hip flexion increased at initial contact } \\
\text { when unloaded compared to loaded }\end{array}$ \\
\hline $\begin{array}{l}\text { Kulas et al. } \\
(2010)\end{array}$ & $\begin{array}{l}45 \mathrm{~cm} \text { two footed } \\
\text { drop landing }\end{array}$ & $\begin{array}{l}\text { Load ( } 10 \% \text { BW } \\
\text { weighted vest) and } \\
\text { trunk adaptation to } \\
\text { load (extensors or } \\
\text { flexors) }\end{array}$ & $\begin{array}{l}\text { Added load increased KASF in trunk } \\
\text { extensors and increased quadriceps and } \\
\text { gastrocnemius forces in both groups. } \\
\text { Hamstring force greater in trunk flexor } \\
\text { group than extensor group when loaded }\end{array}$ \\
\hline $\begin{array}{l}\text { Kulas et al. } \\
(2008)\end{array}$ & $\begin{array}{l}45 \mathrm{~cm} \text { two footed } \\
\text { drop landing }\end{array}$ & $\begin{array}{l}\text { Load ( } 10 \% \text { BW } \\
\text { weighted vest) and } \\
\text { trunk adaptation to } \\
\text { load (extensors or } \\
\text { flexors) }\end{array}$ & $\begin{array}{l}\text { Added trunk load and trunk position } \\
\text { interactively affect hip biomechanics. } \\
\text { Added trunk load increase the } \\
\text { biomechanical demand on the knee and } \\
\text { ankle regardless of trunk position }\end{array}$ \\
\hline $\begin{array}{l}\text { Blackburn et } \\
\text { al. (2009) }\end{array}$ & $\begin{array}{l}60 \mathrm{~cm} \text { two footed } \\
\text { drop landing }\end{array}$ & $\begin{array}{l}\text { Trunk position } \\
\text { (preferred, active } \\
\text { flexion) }\end{array}$ & $\begin{array}{l}\text { Active trunk flexion reduced vGRF and } \\
\text { pGRF and quadriceps muscle activity }\end{array}$ \\
\hline $\begin{array}{l}\text { Kulas et al. } \\
(2012)\end{array}$ & Single leg squat & $\begin{array}{l}\text { Trunk position } \\
\text { (minimise forward } \\
\text { lean, increased } \\
\text { forward lean) }\end{array}$ & $\begin{array}{l}\text { Peak ACL forces reduced when } \\
\text { moderately increasing forward lean }\end{array}$ \\
\hline $\begin{array}{l}\text { Shimokochi } \\
\text { et al. (2013) }\end{array}$ & $\begin{array}{l}\text { Single leg drop } \\
\text { ( } 30 \mathrm{~cm} \text { for } \\
\text { females and } 45 \\
\mathrm{~cm} \text { for males) }\end{array}$ & $\begin{array}{l}\text { Trunk position (self- } \\
\text { selected, forward } \\
\text { lean, upright) }\end{array}$ & $\begin{array}{l}\text { When compared to forward leaning } \\
\text { landing, upright landing showed greater } \\
\text { peak vGRF and peak knee extension } \\
\text { moment, but less plantar flexion, hip } \\
\text { extension moment and muscle activity of } \\
\text { the MG, LG and LQ }\end{array}$ \\
\hline $\begin{array}{l}\text { Dempsey et } \\
\text { al. (2012) }\end{array}$ & $\begin{array}{l}\text { Single leg landing } \\
\text { following a ball } \\
\text { catch }\end{array}$ & $\begin{array}{l}\text { Movement of ball } \\
\text { (ball moved } \\
\text { towards or away } \\
\text { from support leg } \\
\text { both early and late) }\end{array}$ & $\begin{array}{l}\text { Movement of ball towards support leg } \\
\text { resulted in increased knee valgus moment } \\
\text { when compared to ball moving away. } \\
\text { Significant positive correlation between } \\
\text { trunk lateral flexion towards landing leg } \\
\text { and knee valgus moment }\end{array}$ \\
\hline $\begin{array}{l}\text { Nagano et } \\
\text { al. (2011) }\end{array}$ & $180^{\circ}$ cutting & Gender & $\begin{array}{l}\text { Trunk forward and lateral inclination } \\
\text { significantly greater in males than } \\
\text { females. Strong positive correlation } \\
\text { between trunk forward inclination and } \\
\text { knee flexion }\end{array}$ \\
\hline $\begin{array}{l}\text { Frank et al. } \\
(2013)\end{array}$ & $60^{\circ}$ cutting & Trunk motion & $\begin{array}{l}\text { Greater knee varus moment associated } \\
\text { with reduced trunk rotation away from } \\
\text { stance limb (towards direction of travel). }\end{array}$ \\
\hline
\end{tabular}

